\title{
Low Birth Weight Outcomes: Why Better in Cuba Than Alabama?
}

\author{
Yasmin Neggers, DrPH, RD, and Kristi Crowe, PhD, RD, LD
}

Reducing the incidence of low birth weight (LBW), a major predictor of infant mortality and morbidity in developed and developing countries, is an important worldwide goal, yet interventions to reduce this incidence have been disappointingly unsuccessful. Despite its low per capita income, Cuba has managed to significantly reduce the prevalence of $L B W$ in recent decades. To date, minimal research has been conducted to comparatively evaluate risk factors associated with birth weight outcomes between countries with significantly differing rates of LBW. For this reason, we traveled to Havana to study the Cuban model of prenatal care and compare risk factors associated with LBW in Cuba, the United States, and, in particular, Alabama. This article describes the community-based approaches to prenatal care provided within the Cuban healthcare system and their influence on rates of LBW. As a result of these successfully integrated health services, the Cuban healthcare model will be used to evaluate and compare Alabama's current prenatal care system, in particular the implementation of strategies such as community-based clinics and maternity homes for high-risk pregnancies. (J Am Board Fam Med 2013;26:187-195.)

Keywords: Alabama, Cuba, Low Birth Weight, Prenatal Care, Risk Factors

Low birth weight (LBW; $<2500 \mathrm{~g}$ ) is the single most important factor affecting neonatal mortality and a significant determinant of postneonatal mortality. ${ }^{1}$ Furthermore, LBW babies are at an increased risk for serious health problems, ranging from neurodevelopmental disabilities such as cerebral palsy and mental retardation to respiratory disorders. $^{2}$ In the United States, $65 \%$ of all infant deaths result from LBW and preterm birth. ${ }^{1}$

The biological importance of LBW is signified by the fact that the World Health Organization and United Nations International Children's Emergency Fund have a Millennium Development Goal for reducing child mortality; this goal includes developing methods to estimate the global percentage of LBW infants born per year despite the fact that $>50 \%$ of

This article was externally peer reviewed.

Submitted 29 August 2012; revised 29 November 2012; accepted 3 December 2012.

From the Department of Human Nutrition, University of Alabama, Tuscaloosa.

Funding: Funding for travel to Cuba was provided by the Alabama-Cuba Initiative, the College of Arts and Sciences, University of Alabama, Tuscaloosa, AL.

Conflict of interest: none declared.

Corresponding author: Kristi Crowe, Department of Nutrition, University of Alabama, Box 870311, Russell Hall 409, Tuscaloosa, AL 35401 (E-mail: kcrowe@ches.ua.edu). newborns are not weighed at birth. ${ }^{3}$ As expected, there is considerable variation in the percentage of infants with LBW among countries, yet there is a strong association between LBW percentages and infant mortality rates. ${ }^{2}$ In brief, the rates of LBW are highest in most Asian and African countries, followed by Latin America and Caribbean countries; the lowest rates of LBW are in Oceania and Europe. Among developing countries, Cuba remains an enigma to North America and Europe alike. The percentage of LBW in Cuba is not only much lower than its neighboring developing countries such as Jamaica, Haiti, and the Dominican Republic, but is also lower than far more affluent countries such as England and the United States. ${ }^{4}$ Despite a per capita gross domestic product that places Cuba in the fourth quintile of nations, Cuba's infant mortality rate rivals that of Canada and is lower than the average infant mortality rate in the United States and, in particular, the state of Alabama. ${ }^{5}$ According to the current available statistics, the national average rate of LBW in the United States is $7.7 \%$, and Alabama's rate of LBW is $10.4 \% .{ }^{6,7}$ Unfortunately, these rates have not significantly declined since the mid-1980s, especially among African-American women and women 
of low socioeconomic status. ${ }^{7}$ In contrast, in 2009, the rate of LBW for Cuba, as reported by the World Bank World Development Indicators (2011) was only $5.1 \%$, or $50 \%$ lower than the LBW rate in Alabama. ${ }^{8}$ Although interventions to reduce the incidence of LBW in both developed and developing countries have been disappointingly unsuccessful, the percentages of LBW and infant mortality rates have consistently declined in Cuba over the past decade, from a rate of $9.0 \%$ in 1992 to $5.1 \%$ in 2009 (Figure 1). ${ }^{8}$ Such metrics suggest a tailored approach to prenatal care in Cuba that warrants additional investigation.

To date, minimal research has been conducted to comparatively evaluate the established risk factors associated with birth weight outcomes among countries with significantly differing rates of LBW.
For this reason, we searched the available literature about Cuba to estimate and compare the prevalence of known risk factors associated with LBW in Cuba and the United States, particularly in Alabama. In addition, we traveled to Cuba in February 2012 to meet with doctors, researchers, and maternal health care professionals at the Institute of Nutrition and Hygiene and the University of Havana for the purpose of discussing these significant differences and the Cuban methods and integrated services used to reduce the incidence of LBW.

\section{Comparing Risk Factors Associated With LBW in Cuba and Alabama}

Although there are numerous factors associated with LBW, the major risk factors include maternal

Figure 1. Trends in percentage of low birth weight (LBW) for Cuba and USA from 1960-2010. Adapted from Index Mundi $^{8}$ based on data from the World Bank. ${ }^{8}$ Source: UNICEF, State of the World's Children, Child Info, and Demographic and Health Survey by Macro International, $2011 .^{8}$

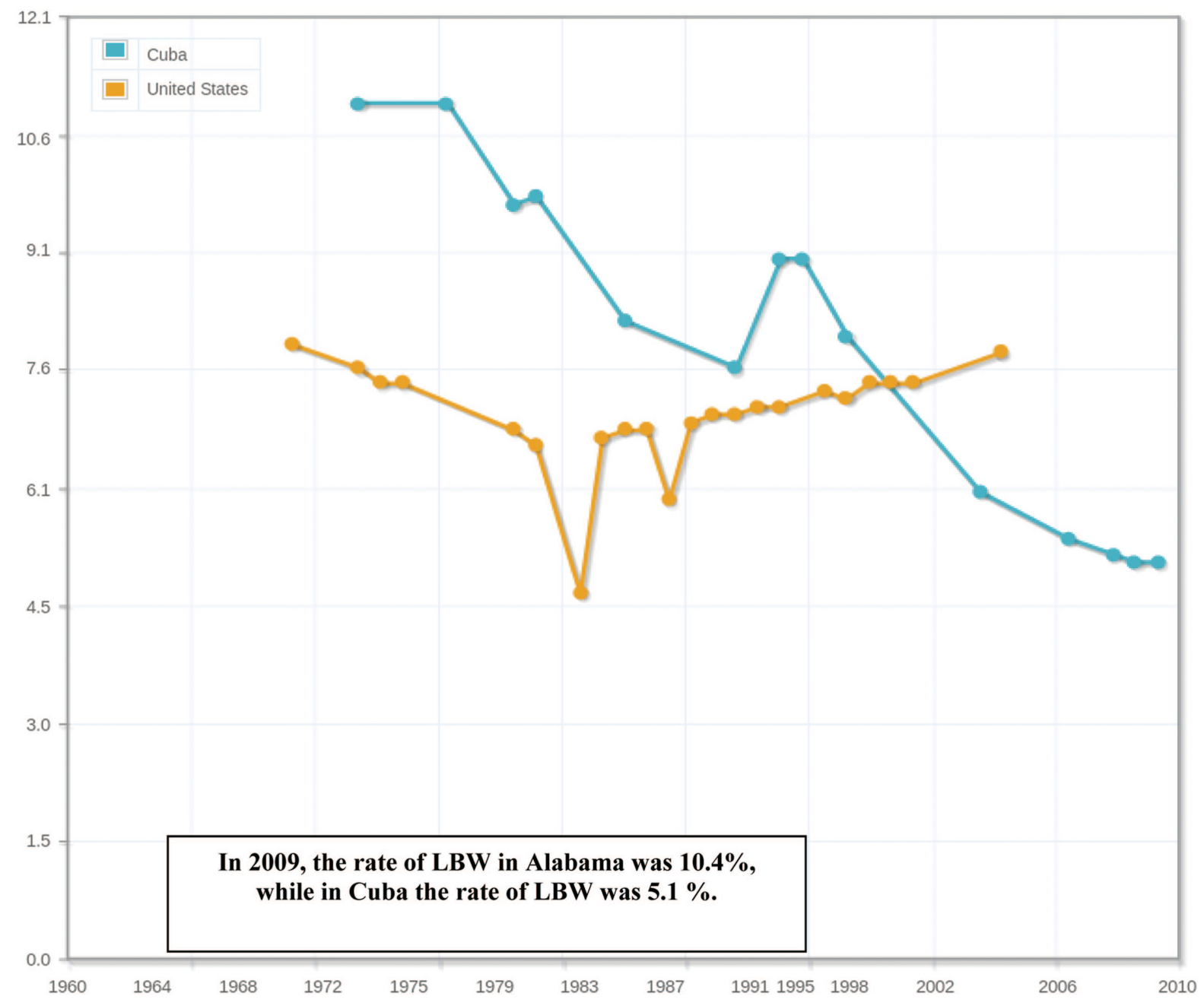


age, race, weight before pregnancy, weight gain during pregnancy, prenatal care, and use of tobacco and alcohol products. ${ }^{9}$ Socioeconomic conditions, nutrition during pregnancy, and anemia are also key factors that have been proven to influence the prevalence of LBW. In comparing the major risk factors between Cuba and the United States, particularly Alabama, prenatal care is the risk factor that is significantly better in Cuba. In contrast, there is a lower prevalence of several major risk factors for LBW, including smoking, anemia, and weight gain during pregnancy, in the United States and Alabama compared with Cuba. Although additional differences may exist in prevalence of risk factors between the countries, these were the only 4 for which there are data available to perform a comparative assessment. As such, the following sections draw contrast to the significant differences in the prevalence of these 4 risk factors in Cuba and Alabama.

\section{Smoking}

Smoking during pregnancy is among the leading preventable causes of adverse fetal outcomes such as LBW, small for gestational age, stillbirth, and sudden infant death syndrome. ${ }^{10}$ Because only a minority of women of childbearing age manages to quit smoking when they become pregnant, smoking among young women is the primary determinant of the prevalence of smoking during pregnancy. ${ }^{11}$ During the past several decades, smoking among women of reproductive age has decreased in the United States. In 1965, 44\% of women aged 25 to 44 years smoked. In 2000, these rates decreased to $23 \% .^{11}$ In Alabama in $2009,11.3 \%$ of 20 - to 34-year-old women and $7.5 \%$ of women aged 35 and older reported smoking during pregnancy. ${ }^{7}$ Among Cuban women, the latest statistics available reported a smoking prevalence of $26.3 \%$ for women aged $\geq 15$ years, according to the Pan American Health Organization ${ }^{12,13}$; furthermore, results of a descriptive population-based study using smoking prevalence and mortality data in Cuba from 1995 and 2007 indicated that $15 \%$ and $16 \%$ of preventable deaths, respectively, were attributed to smoking. ${ }^{14}$

\section{Anemia}

Anemia is a global public health problem affecting both developed and developing countries. The resulting effect of anemia on pregnancy outcomes includes increased risk of maternal mortality, infant mortality, and poor fetal growth resulting in LBW. ${ }^{15}$ According to the World Health Organization Global Database on Anemia published in 2008, the estimate of anemia among pregnant women the United States was $5.7 \%$ (95\% confidence interval $[\mathrm{CI}], 3.6-8.9) .{ }^{16}$ As a public health problem in the United States, anemia was rated as mild. ${ }^{16}$ According to the same database, the prevalence of anemia in pregnant women in Cuba was $39.1 \%$ (95\% CI, 14.0-71.5). As a public health problem in Cuba, anemia was rated as moderate. Overall, iron deficiency anemia is the most common nutritional problem in Cuba. ${ }^{13}$ The updated dietary reference intake for Cuba (published in 2008) recommends an intake of $30 \mathrm{mg}$ iron/day for pregnant women, which is higher than $27 \mathrm{mg} /$ day recommended for pregnant women in the United States. ${ }^{17}$

\section{Weight Gain During Pregnancy}

Weight gain during pregnancy is a significant predictor of infant birth weight; furthermore, weight gain below recommended ranges correlates with increased infant mortality and LBW. ${ }^{18}$ The United States currently uses recommendations by the Institute of Medicine that are based on prepregnancy body mass index (BMI) categories and data on gains associated with the birth of healthy-sized newborns (approximately $3500-4500 \mathrm{~g}$, or $7 \mathrm{lb} 13 \mathrm{oz}$ to 10 lb). ${ }^{19}$ For all gravidas except those deemed obese according to BMI (BMI $>30$ to $40 \mathrm{~kg} / \mathrm{m}^{2}$ ), women who gain weight within these recommended ranges are half as likely to deliver newborns with LBW or who are small for gestational age compared with women who gain less. ${ }^{20}$ Pregnancy weight gain below the recommended ranges is associated with increased infant mortality and LBW. According to the data, approximately $40 \%$ of U.S. women gain within the recommended weight ranges during pregnancy. ${ }^{21}$ Studies conducted in Cuba indicate that a total weight gain of $<8 \mathrm{~kg}$ during pregnancy increases the risk of LBW. ${ }^{21,22}$ For example, Escobar et $\mathrm{al}^{21}$ reported an adjusted odds ratio (RPO) of 3.27 (95\% CI, 2.52-4.24) for LBW among women who gained $<8 \mathrm{~kg}$ during pregnancy compared with those women who gained $>8 \mathrm{~kg}$ during pregnancy. During the years spanning 1984 to 1990 , the nutrition surveillance indicators used to guide the maternal care process in Cuba included (1) low weight/height at the beginning of pregnancy (below the 10th percentile of Cuban reference values), 
(2) insufficient weight gain $(<8 \mathrm{~kg}$ at the end of pregnancy) and, (3) anemia (hemoglobin levels $<11 \mathrm{~g} / \mathrm{dL}$ ) during the third trimester. ${ }^{23}$ The percentages of pregnant women at risk according to these 3 indicators were $8.7 \%, 5.5 \%$, and $11.4 \%$, respectively.

\section{Prenatal Care}

In the United States, the efficacy of prenatal care to lower infant LBW and infant mortality is controversial, and some researchers believe that it is difficult to evaluate the association between quality of prenatal care and birth outcomes. ${ }^{24} \mathrm{With}$ regard to adequate prenatal care (care initiated by the fourth month of pregnancy with $80 \%$ of recommended prenatal visits made), maternal and child health statistics in Alabama in 2009 indicated that only $72 \%$ of women received adequate prenatal care; several counties in Alabama reported that less than half $(47.5 \%)$ of pregnant women receive adequate prenatal care. ${ }^{7,25}$

In Cuba, the centralized Maternal-Child Program (Programa Nacional de Atencion Materno-infantil, or PAM) was established in 1970. PAM has the main responsibility of assuring the health of women of childbearing age. The success of PAM's efforts is documented by one of the most rapid declines in infant mortality ever recorded. ${ }^{26}$ Under the leadership of this program, governmental sectors as well as community organizations collaborate to provide prenatal care and other health services to women and their children. Such services include free screening and diagnostic testing as well as the availability of maternity homes in every municipality to provide medical assistance and nutritionally balanced, calorically dense meals 24 hours/day to women with high-risk pregnancies. ${ }^{26,27}$ According to World Bank data, $100 \%$ of pregnant Cuban women receive prenatal care, defined as medical and nursing care recommended for women before and during pregnancy. ${ }^{3,6,28}$ Likewise, in Cuba the average number of prenatal visits per woman increased from 17.2 in 1992 to 23.6 in $1996 .^{13}$

Although in most countries interventions to reduce the incidence of LBW are largely unsuccessful, implementation of universal health care with a strong focus on community-based services for prenatal care in Cuba has significantly reduced the prevalence of LBW over the past 20 years. ${ }^{5}$ For example, the MEDICC Review Cuba Health Report for Havana City indicates that the infant mortality rate, which was oscillating between 6.6 and 7.1 per 1000 live births since 2001, dropped to 4.9 in 2006 , and the prevalence of LBW decreased from 5.6 to $5.4^{29}$ As quoted within the report, the vice director of Havana's Health Department, in charge of the city's medical services, attributed most of this decline to well-integrated universal primary and secondary health care, particularly specialized prenatal care for high-risk pregnant women.

After reviewing the available research, we came to the conclusion that a strong emphasis on prenatal care, including integrated health services such as community-based clinics and maternity homes, particularly in disadvantaged communities in Alabama, may reduce the prevalence of LBW infants. With a modest investment in infrastructure combined with extensive public health strategy, education, and effective communication, Alabamians would be expected to benefit from a modified $\mathrm{Cu}-$ ban approach. With this hypothesis in mind, we traveled to Cuba to study the community-based approaches to prenatal care provided within the Cuban health care system, which has significantly reduced the rate of LBW and infant mortality in that country.

\section{The Cuban Approach to Monitoring Pregnancy Outcomes}

In recent years, several articles have documented the Cuban primary health care system; to date, however, no research has been conducted to document the methodology and measurements used within the Cuban Health System for evaluating the nutritional status of pregnant women. Given the historical landscape of Cuba and its influence on population dynamics, including nutrition and food security, anthropometric charts developed outside of Cuba would not be expected to accurately reflect the Cuban population. For this reason, nutrition scientists at the Institute of Food and Hygiene with the support of United Nations International Children's Emergency Fund developed pregnancy weight gain guidelines and measurements for use within community-based clinics and maternity homes in Cuba. During our visit to Havana, we met with the developers of these guidelines and with researchers at the College of San Geronimo and the University of Havana. From these meetings, we focused our attention on 3 primary features unique to the $\mathrm{Cu}$ ban health care system that differ from prenatal 
care approaches in the United States and Alabama. These include population-specific pregnancy weight gain guidelines, frequency of maternal clinic visits and screenings throughout pregnancy, and routine provision of free vitamin supplements to pregnant women.

\section{Development of Cuban Weight Gain Guidelines}

Data collected for the development of pregnancy weight gain guidelines for Cuban women was conducted over a 3-year period, during which nurses and dietitians in 15 municipalities around Havana were trained to accurately collect anthropometric data at the first prenatal care visit and subsequent visits throughout gravida. ${ }^{30}$ The sample population from which data were collected to develop these nutritional assessment materials consisted of 6750 pregnant women between the ages of 20 and 39 years. Hierarchical linear models were applied to collected data to carry out predictions necessary to build charts of attained weight recommendations for gestational age according to height. Following multilevel modeling and statistical validation, 12 charts with recommended weight by gestational age for height were developed to assist the primary care team within each municipality and maternity home in evaluating the nutritional status of women during pregnancy. In addition, these charts were used to develop the Cuban Pregnancy Weight Gain Guidelines. These guidelines and measurements are used by health care personnel to classify gravidas as low, moderate, or high risk according to their initial BMI and subsequent weight gain during the second and third trimesters (Table 1).

\section{Clinic Visits and Screenings During Pregnancy}

Innate to the Cuban health care system, primary care physicians conduct 2 visits per year with each resident within their assigned municipality. The frequency of these visits is mandated by the Cuban government, and all physicians are held accountable for health care outcomes within the community that they serve, such that their employment as a community physician is based on the consistency of appropriate health outcomes and health care goals set by the government. For example, specific outcomes related to pregnancy for which community physicians are held accountable include incidence of LBW and infant mortality.

Upon conception, pregnant women are seen once per month during the first 33 weeks of pregnancy. At the first visit following conception, the
Table 1. Cuban Pregnancy Weight Gain Guidelines ${ }^{25}$

\begin{tabular}{|c|c|c|c|}
\hline \multirow{2}{*}{$\begin{array}{l}\text { BMI }\left(\mathrm{kg} / \mathrm{m}^{2}\right) \text { at } \\
\text { Beginning by } \\
\text { Trimester of } \\
\text { Gestation }\end{array}$} & \multicolumn{3}{|c|}{ Weekly Weight Gain (kg) } \\
\hline & Low & Moderate & High \\
\hline \multicolumn{4}{|l|}{ Underweight ( $\leq 18.8$ ) } \\
\hline Second & $0.34-0.42$ & $0.43-0.69$ & $0.70-0.78$ \\
\hline Third & $0.26-0.34$ & $0.35-0.61$ & $0.62-0.70$ \\
\hline \multicolumn{4}{|c|}{$\begin{array}{l}\text { Normal weight }(>18.8 \\
\text { to }<25.6)\end{array}$} \\
\hline Second & $0.30-0.39$ & $0.40-0.66$ & $0.67-0.75$ \\
\hline Third & $0.23-0.31$ & $0.32-0.58$ & $0.59-0.67$ \\
\hline \multicolumn{4}{|l|}{$\begin{array}{l}\text { Overweight }(\geq 25.6 \text { to } \\
<28.6)\end{array}$} \\
\hline Second & $0.27-0.34$ & $0.35-0.63$ & $0.64-0.71$ \\
\hline Third & $0.20-0.28$ & $0.29-0.53$ & $0.54-0.61$ \\
\hline \multicolumn{4}{|l|}{ Obese $(\geq 28.6)$} \\
\hline Second & $0.17-0.26$ & $0.27-0.53$ & $0.54-0.64$ \\
\hline \multirow[t]{3}{*}{ Third } & $0.15-0.23$ & $0.24-0.48$ & $0.49-0.56$ \\
\hline & \multicolumn{3}{|c|}{$\begin{array}{c}\text { Cumulative Weight Gain (kg) for } \\
\text { Trimester }\end{array}$} \\
\hline & Low & Moderate & High \\
\hline \multicolumn{4}{|l|}{ Underweight ( $\leq 18.8$ ) } \\
\hline Second & $4.42-5.46$ & $5.59-8.96$ & $9.10-10.14$ \\
\hline Third & $3.64-4.76$ & $4.90-8.53$ & $8.68-9.80$ \\
\hline Second and third & $9.45-11.33$ & $11.34-17.28$ & $17.29-19.17$ \\
\hline \multicolumn{4}{|c|}{$\begin{array}{l}\text { Normal weight }(>18.8 \\
\text { to }<25.6)\end{array}$} \\
\hline Second & $3.90-5.07$ & $5.20-8.57$ & $8.71-9.75$ \\
\hline Third & $3.22-4.34$ & $4.51-8.09$ & $8.26-9.38$ \\
\hline Second and third & $8.64-10.52$ & $10.53-15.93$ & 15.94-18.09 \\
\hline \multicolumn{4}{|l|}{$\begin{array}{l}\text { Overweight ( } \geq 25.6 \text { to } \\
\quad<28.6)\end{array}$} \\
\hline Second & $3.51-4.42$ & $4.57-8.16$ & $8.32-9.23$ \\
\hline Third & $2.80-3.92$ & $4.02-7.45$ & $7.56-8.54$ \\
\hline Second and third & $7.56-9.44$ & $9.45-14.85$ & $14.86-16.47$ \\
\hline \multicolumn{4}{|l|}{ Obese $(\geq 28.6)$} \\
\hline Second & $2.21-3.38$ & $3.51-6.88$ & $7.02-8.32$ \\
\hline Third & $2.10-3.22$ & $3.35-6.72$ & $6.86-7.84$ \\
\hline Second and third & $5.40-7.55$ & $7.56-12.96$ & $12.97-14.58$ \\
\hline
\end{tabular}

BMI, body mass index.

level of nutritional risk will be determined using the mother's initial BMI. Additional measures of pre- and postnatal care are provided in Table 2. If the pregnancy is categorized as high risk according to the Cuban Pregnancy Weight Gain Guidelines, women are seen at more frequent intervals or referred to a maternity home for the duration of their pregnancy. In addition, all pregnancies deemed high risk will follow a "partogram" ("delivery gram") or critical care route outlined for all clinicians attending to these women. ${ }^{29}$ Under this in- 
Table 2. Prenatal and Postnatal Care, Measurements, and Support Provided Through the Cuban Health Care System

\begin{tabular}{|c|c|c|c|c|}
\hline \multicolumn{3}{|l|}{ Prenatal Care } & \multicolumn{2}{|c|}{ Postnatal Care } \\
\hline Medical Visits & \multicolumn{2}{|c|}{ Frequency } & Medical Visits & Frequency \\
\hline Weeks 12-33 & \multicolumn{2}{|c|}{1 per month } & Upon Birth & - \\
\hline Weeks 34-38 & \multicolumn{2}{|c|}{2 per month } & Weeks 2-12 & 1 per week \\
\hline Weeks $\geq 38$ & \multicolumn{2}{|c|}{ Weekly } & Weeks $13-52$ & 1 per month \\
\hline \multicolumn{3}{|c|}{ Maternal Measurements } & \multicolumn{2}{|c|}{ Infant Measurements } \\
\hline \multicolumn{3}{|l|}{ Initial BMI } & \multicolumn{2}{|c|}{ Weight for age } \\
\hline \multicolumn{3}{|c|}{ Blood pressure (each visit) } & \multicolumn{2}{|c|}{ Length for age } \\
\hline \multicolumn{3}{|c|}{$\begin{array}{l}\text { Weight gain and BMI (each visit } \\
\text { after } 14 \text { weeks) }\end{array}$} & \multicolumn{2}{|c|}{ Head circumference } \\
\hline \multicolumn{3}{|c|}{ Ultrasound (12, 20, and 32 weeks) } & \multicolumn{2}{|c|}{$\begin{array}{l}\text { Vaccination (according } \\
\text { to national schedule) }\end{array}$} \\
\hline \multicolumn{5}{|c|}{$\begin{array}{l}\text { Uterus height, abdominal } \\
\text { circumference (each visit after } \\
14 \text { weeks) }\end{array}$} \\
\hline \multicolumn{5}{|c|}{$\begin{array}{l}\text { Typhus immunization (between } \\
24 \text { and } 28 \text { weeks) }\end{array}$} \\
\hline \multicolumn{5}{|c|}{ Blood glucose (as needed) } \\
\hline \multicolumn{5}{|c|}{ Hemoglobin (as needed) } \\
\hline \multicolumn{5}{|c|}{ Additional Maternal Support } \\
\hline \multicolumn{2}{|c|}{ Health education } & \multicolumn{3}{|c|}{$\begin{array}{l}\text { Early and exclusive breastfeeding } \\
\text { support }\end{array}$} \\
\hline \multicolumn{2}{|c|}{ Personal hygiene care } & \multicolumn{3}{|c|}{$\begin{array}{l}\text { Promotion of home-based } \\
\text { newborn care }\end{array}$} \\
\hline \multicolumn{2}{|c|}{$\begin{array}{l}\text { Psychological } \\
\text { support/counseling }\end{array}$} & \multicolumn{3}{|c|}{ Family planning counseling } \\
\hline \multicolumn{2}{|c|}{ Nutrition counseling } & \multicolumn{3}{|c|}{ Nutrition counseling } \\
\hline \multicolumn{5}{|c|}{ Maternal vitamin \& mineral } \\
\hline
\end{tabular}

BMI, body mass index.

novative care plan, the care of each gravida will be transferred early in the pregnancy to the bestsuited physicians and hospitals for delivering the newborns based on the individual conditions that place them at high risk. For all normal to moderate-risk pregnancies, twice monthly visits will occur during weeks 34 through 38, after which time weekly visits are initiated. Unique to the "Cuban model" is the fact that if the pregnant woman fails to show up to a clinic visit, the primary care physician will visit the home for the required visit. Also of interest, primary care physicians within each municipality deliver infants unless complications arise that warrant an obstetrician. In keeping with the comprehensive approach to health care in Cuba, the newborn and its mother are seen weekly by their primary care physician through the first 3 months of life, after which time mother and child will transition to monthly visits through the first year of life. Such comprehensive approaches to providing adequate primary care in Cuba have assisted the country in accomplishing an infant mortality rate lower than most other Latin American countries and United States and similar to that of Canada $^{26}$ (Figure 2).

\section{Maternal Vitamin Supplementation}

Within the Cuban health care system, all women who achieve menarche are provided iron, vitamin C, folic acid, and vitamin A supplements at no cost (personal communication, Dr. Maria Elena Diaz, professor and Chair of the Institute of Nutrition and Hygiene, Havana, Cuba, February 7, 2011). In addition, increased amounts of these same nutrients are provided routinely as maternal vitamin supplements at conception through the infant's first year of life as a feature of the prenatal care services provided at no cost to pregnant women. In addition to the free provision of maternal supplements, the Cuban population must consume a daily multivitamin at a minimal cost assumed by each individual. This government directive on multivitamin supplementation is tracked and reported by individual pharmacies selling the supplements, is supervised by the community physician at yearly visits, and is reported by the physician. Although the multivitamin must currently be purchased by individuals, the government dispensed the multivitamins doorto-door free of charge during preceding decades when the health of the Cuban population was suboptimal. The exact mechanism of tracking and reproach for not taking government-sponsored vitamins is not information that was divulged. Table 3 contrasts the Institute of Medicine's prenatal supplement recommendations for women at risk of deficiency with those nutrients provided by the Cuban multivitamin and maternal supplements. ${ }^{31}$ Regardless of the difference between recommendations and intake of supplements or the potential for patriotic reporting bias over the current health care system, Cuban birth weight outcomes are significantly better than most Western countries, and the provision of free maternal supplements is a remarkable feature of the Cuban approach to prenatal care. 
Figure 2. Trends in infant mortality rate in Cuba and the U.S., 1960-2010. (Data source: World Bank, World Development Indicators.)

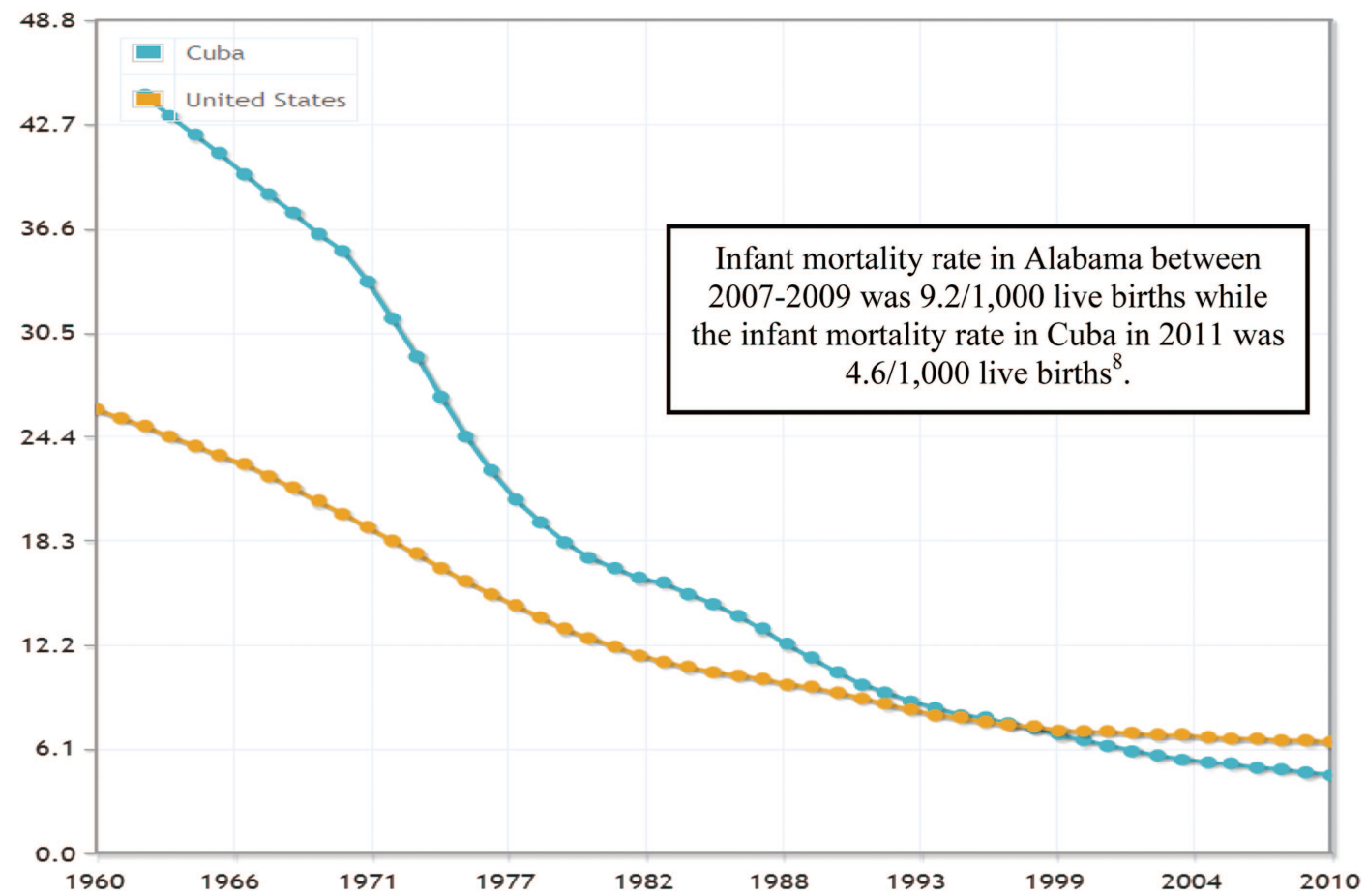

\section{Examples of Potential Programs to Change Prenatal Care Consistent With the Cuban Approach}

There are several examples outlined below for implementing community-based prenatal care in the

Table 3. Comparison of Prenatal Supplement Provision Through the Cuban Healthcare System and the Prenatal Supplement Guidelines for Women at Risk of Deficiency According to the Institute of Medicine

\begin{tabular}{lccc}
\hline Nutrient & $\begin{array}{c}\text { IOM } \\
\text { Recommendation }\end{array}$ & $\begin{array}{c}\text { Cuban } \\
\text { Multivitamin } \\
\text { Provision }\end{array}$ & $\begin{array}{c}\text { Cuban } \\
\text { Prenatal } \\
\text { Supplement }\end{array}$ \\
\hline Iron & $30-60 \mathrm{mg}$ & & $86 \mathrm{mg}$ \\
Zinc & $15 \mathrm{mg}$ & & \\
Copper & $2 \mathrm{mg}$ & & \\
Calcium & $250 \mathrm{mg}$ & $2500 \mathrm{IU}$ & $2000 \mathrm{IU}$ \\
Vitamin A & & & $35 \mathrm{mg}$ \\
Vitamin C & $50 \mathrm{mg}$ & & \\
Vitamin D & $400 \mathrm{IU}$ & $0.25 \mathrm{mg}$ & $250 \mu \mathrm{g}$ \\
Folic acid & $400 \mu \mathrm{g}$ & $2.5 \mathrm{mg}$ & \\
Vitamin $\mathrm{B}_{1}$ & & $1.6 \mathrm{mg}$ & \\
Vitamin $\mathrm{B}_{2}$ & & $20 \mathrm{mg}$ & \\
Vitamin $\mathrm{B}_{3}$ & & $2 \mathrm{mg}$ & \\
Vitamin $\mathrm{B}_{6}$ & $2 \mathrm{mg}$ & $6 \mu \mathrm{g}$ & \\
Vitamin $\mathrm{B}_{12}$ & $2 \mu \mathrm{g}$ & & \\
\hline
\end{tabular}

IOM, Institute of Medicine.
United States that will be considered for adaptation on a pilot scale. ${ }^{32,33}$ In Alabama, efforts to develop outcome-based, community-oriented maternity clinics/homes are feasible in light of a major impetus from the Patient Protection and Affordable Care Act, which emphasizes preventive- and outcome-based medicine.

North Carolina, which is culturally similar to Alabama, recently (March 2012) started The Pregnancy Medical Home (PMH) program through cooperation between the North Carolina Division of Medical Assistance and the NC Division of Public Health and Community Care of North Carolina. ${ }^{32}$ The $\mathrm{PMH}$ program provides comprehensive, coordinated maternity care to pregnant Medicaid patients within 14 local networks of Community Care of North Carolina. Within each network, an obstetrician and an obstetric nurse coordinator are responsible for recruiting pregnant women and supporting practices adopted as part of the $\mathrm{PMH}$ program to reduce the incidence of LBW.

Another attractive approach for implementing community-based prenatal care in Alabama is a pilot program in cooperation with family practice physicians in the College of Community Health Sciences at the University of Alabama. In this pro- 
gram, local midwives, nurse practitioners, and social workers would work in conjunction with family physicians to provide comprehensive, coordinated, and integrated prenatal care within a single institutional setting. Recruitment assistance for this pilot program would be made possible through the Obstetrics and Gynecology Clinic at the College of Community Health Science's Family Practice Center, which currently serves mostly low-income, uninsured, or Medicaid patients. Since patient information and results of medical tests conducted at the Family Practice Clinic are fully computerized in one location, data collection as part of the pilot program could be accomplished through existing protocols.

Last, local churches may provide a practical vehicle for implementation of community-based prenatal care approaches. For example, a church-affiliated maternity home recently was opened in the small community of Fosters, Alabama, to house and provide prenatal care for up to 12 pregnant women. ${ }^{34}$ The long-term effects of programs such as these are yet to be determined and would need to be followed and improved on for further implementation throughout rural and urban areas of Alabama.

\section{Conclusions}

Although country-specific guidelines such as these are unique, the well-integrated Cuban approach to adequate primary care during pregnancy coupled with significantly lower rates of LBW and infant mortality warrant additional investigation as to the broader significance of population-specific guidelines and approaches across a broad range of economically challenged countries. With regard to the state of Alabama, the Cuban health care model represents a model system for evaluation and comparison with the state's current prenatal care system and policies. Implementation of strategies such as community-based clinics and maternity homes for high-risk pregnancies, similar to those implemented in Cuba, along with routine vitamin/mineral supplementation at no cost to pregnant women have the potential to significantly improve birth weight outcomes among Alabamians and the United States as a whole. Modifying existing prenatal care practice in the United States to a more flexible model, with frequency, content, and timing designed to meet maternal and fetal risk, may improve poor birth out- comes such as LBW. Given the challenges of providing affordable health care, sincere investigations and discussions of these strategies must occur at both the medical and governmental levels to effectively impact the health of future generations.

The authors acknowledge Dr. Maria Elena Diaz, Professor and Chair of the Institute of Nutrition and Hygiene, Havana, Cuba, for her expertise about prenatal care in Cuba.

\section{References}

1. Goldenberg RL, Culhane JF, Iams JD, Romero R. Epidemiology and causes of preterm birth. Lancet 2008;371:75-82.

2. The United Nations Children's Fund and World Health Organization. Low birthweight. Country regional and global estimates. Geneva, Switzerland: WHO Publications; 2004.

3. Lopez NB, Choonara I. Can we reduce the number of low birth-weight babies? The Cuban experience. Neonatology 2009;95:193-7.

4. Dresang LT, Brebrick L, Murray D, Shallue A, Sullivan-Vedder L. Family medicine in Cuba: community-oriented primary care and complementary and alternative medicine. J Am Board Fam Pract 2005;18:297-303.

5. Keon WJ. Cuba's system of maternal health and early childhood development: lessons for Canada. CMJA 2009;180:314-6.

6. CDC Pediatric and Pregnancy Nutrition Surveillance System. When: Is low birthweight increasing or decreasing over time? Available from: http:/www. cdc.gov/pednss/how_to/interpret_data/case_studies/ low_birthweight/when.htm. Accessed August 29, 2011.

7. Alabama Department of Health, Center for Health Statistics, Division of Statistical Analyses. Selected maternal child health statistics, Alabama 2009. November 2010. Available from: http://www.adph.org/ healthstats/. Accessed October 10, 2012.

8. UNICEF, Index Mundi. Cuba-low birthweight babies (\% of births). Available from: http://www.indexmundi. com/facts/cuba/low-birthweight-babies. Accessed January 5, 2013.

9. Mathews TJ, MacDorman MF. Infant mortality statistics from the 2004 period linked birth/infant death data set. Natl Vital Stat Rep 2007;55:1-32.

10. Pampel FC. Global patterns and determinants of sex differences in smoking. Int J Comp Sociol 2006;47: 466-87.

11. Murin S, Rafi R, Bilello K. Smoking and smoking cessation in pregnancy. Clin Chest Med 2011;32:75-91.

12. Health statistics (smoking prevalence, females, \%) of adults (most recent) by country. Available from: http:// www.nationmaster.com/graph/hea_smo_pre_fem_of_ adu-health-smoking-prevalence-females-adults. 
13. Bernal S. Women's health care in Cuba: observation of medical facilities in Cerro Havana. International Perspectives. Focus on Cuba. Vol 1. J California State Univ, San Bernadino's International Institute; 2001.

14. Varona P, Herrera D, Garciá RG, Bonet M, Romero T, Venero SJ. Smoking-attributable mortality in Cuba. MEDICC Rev 2009;11: 43-7.

15. Institute of Medicine. Iron nutrition during pregnancy. In: Nutrition During Pregnancy. Part II. Nutrient Supplements. Washington, DC: National Academy Press; 1990;272-98.

16. de Benoist B, McLean E, Egll I, Cogswell M. Worldwide prevalence of anemia 1993-2005: WHO Global Database on Anemia. Geneva: World Health Organization; 2008.

17. Hernandez-Triana M, Porrata C, Jimmmnez S, et al. Dietary reference intake for the Cuban population, 2008. MEDICC Rev 2009;11:9-16.

18. Neggers YH, Goldenberg RL. Some thoughts on body mass index, micronutrient intakes and pregnancy outcome. J Nutr 2003;133:1S-4S.

19. Rasmussen KM, Yaktine AL, editors. Weight gain during pregnancy. Re-examining the guidelines. Washington, DC: Institute of Medicine and $\mathrm{Na}$ tional Research Council, National Academies Press; 2009.

20. Brown JE, Isaacs JS, Krinke UB, et al. Nutrition during pregnancy. In: Nutrition Through Life Cycle. 4th ed. Belmont, CA: Wadsworth, Cengage Publishers, 2011;104-5.

21. Escobar JA, Darias LS, Espinosa MA, et al. Risk factors for low birthweight in a Cuban hospital. 1997-2000. Rev Panam Salud Publica 2002;12: $180-4$.
22. Stusser R, Paz G, Ortega M, et al. Risk of low birth weight in the Plaza de la Habana region. Bol Oficina Sanit Panam 1993;114:229-41.

23. Amador M, Peem M. Nutrition and health issues in Cuba: strategies for a developing country. Food Nutr Bull 1991;13:1-75.

24. Krans EE, Davis MM. Preventing low birthweight: 25 years, prenatal risk, and the failure to reinvent prenatal care. Am J Obstet Gynecol 2012;206:398-403.

26. Cooper RS, Kennelly JF, Ordunez-Garcia P. Health in Cuba. Int J Epidemiol 2006;35:817-24.

27. Gorry C. Cuban maternity homes: a model to address at risk pregnancy. MEDICC Rev 2011;13: $12-5$.

29. Reed G. The story behind Cuba's decline in infant mortality. Cuba Health Reports. Available from: http:// medicc.org/cubahealthreports/chr-artcle.php? \&a = 1026. Accessed October 4, 2011.

30. Díaz ME, Montero M, Jiménez S, Wong I, Moreno V. Diseño y confección de las tablas antropométricas de la embarazada cubana. La Habana: INHA,UNICEF; 2008.

31. Heimburger DC, Ard JD. Handbook of Clinical Nutrition. 4th ed. Philadelphia: Mosby Elsevier; 2006.

32. Community Care of North Carolina. Pregnancy medical home: better care, better birth outcomes. Available from: http://www.communitycarenc.org/ emerging-initiatives/pregnancy-home. Access January $5,2013$.

33. Tinajero AM. Pregnancy outcomes in an initiative preceeding onset of prenatal care. Med Health R I 2012;95:94-197.

34. Harris B. Church's gift helps build new facility. Tuscaloosa News, October 13, 2012. 